\title{
Medievalista
}

Online

$27 \mid 2020$

Número 27

\section{O rei que esmorece e a rainha sanhuda}

a crise dinástica de 1383-1385 através das emoções nas crónicas de Fernão Lopes

The king that faints and the angry queen: the dynastic crisis of 1383-1385

through emotions in the chronicles of Fernão Lopes

Inês Olaia

\section{OpenEdition}

\section{Journals}

Edição electrónica

URL: http://journals.openedition.org/medievalista/2804

ISSN: 1646-740X

\section{Editora}

Instituto de Estudos Medievais - FCSH-UNL

Refêrencia eletrónica

Inês Olaia, "O rei que esmorece e a rainha sanhuda », Medievalista [Online], 27 | 2020, posto online no dia 01 janeiro 2020, consultado o 28 dezembro 2019. URL : http://journals.openedition.org/ medievalista/2804

Mediavalista está licenciado com uma Licença Creative Commons - Atribuição-NãoComercial 4.0 Internacional. 
Título / Title (Português e Inglês): $O$ rei que esmorece e a rainha sanhuda: a crise dinástica de 1383-1385 através das emoções nas crónicas de Fernão Lopes / The king that faints and the angry queen: the dynastic crisis of 1383-1385 through emotions in the chronicles of Fernão Lopes

Autor(es) / Author(s): Inês Olaia

Afiliação institucional / Institutional affiliation (Universidade, Faculdade, Departamento ou Unidade de Investigação / University, Faculty, Department or Research Centre): Centro de História, Departamento de História, Faculdade de Letras, Universidade de Lisboa

Código postal / Postcode; Cidade / City; País / Country: 1600-214 Lisboa, Portugal ORCID: https://orcid.org/0000-0003-0528-4666

Email Institucional / Institutional email: inesolaia@campus.ul.pt Fonte: Medievalista [Em linha]. Direc. Bernardo Vasconcelos e Sousa. Lisboa: IEM. Disponível em: http://www2.fcsh.unl.pt/iem/medievalista/MEDIEVALISTA27/olaia2701.htmI ISSN: 1646-740X

DOI : 10.4000/medievalista.2804

Data recepção do artigo / Received for publication: 12 de Outubro de 2018

Data aceitação do artigo / Accepted in revised form: 29 de Abril de 2019 


\section{Resumo}

A crise dinástica de 1383-1385 foi alvo de estudo por gerações de historiadores. Este artigo pretende contribuir para o debate através de um campo florescente da historiografia que não parece ter ainda sido utilizado para analisar o relato principal dos acontecimentos, da pena de Fernão Lopes: a História das Emoções. Estudaremos assim a paleta emocional expressa pelo cronista-mor do reino e percecionada pelos leitores das crónicas do Portugal Medieval, no sentido de entender como é que sustenta a subida ao trono do Mestre de Avis. $\mathrm{O}$ artigo encontra-se estruturado em torno de três casais régios e das emoções por eles exprimidas e provocadas: Leonor Teles e D. Fernando, como o mau exemplo, pelo desregramento emocional que conduz o reino ao caos e a desadequação dos papéis que desempenham àquilo que deles se espera; Juan I de Castela e Beatriz de Portugal, que pontuam pelo desespero e emoções negativas que provocam; João I e Filipa de Lencastre, como retorno à normalidade, pelo bom desempenho, regrado e positivo. Em todos eles, é o primeiro elemento enunciado que domina as referências.

Palavras-chave: Crise de 1383-1385, História das emoções, Fernão Lopes.

\section{Abstract}

The 1383-1385 dynastic crisis has been studied by generations of historians. This article aims to contribute to the debate through a florescent historiographical field that does not seem to have been used to analyse the main narrative of the events, written by Fernão Lopes: the History of Emotions. We will study the emotional palette expressed by the kingdom's official chronicler and perceived by his Portuguese medieval readers in an attempt to understand how it sustains the rise to the throne of the Master of the Military Order of Avis. The work is structured around three royal couples and the emotions expressed and provoked by them: Leonor Teles and D. Fernando as the bad example because of their emotional imbalance that drives the kingdom to chaos and the inadequacy of the roles they play to what is expected from them; Juan I of Castile and Beatriz of Portugal who arise despair and negative emotions; João I and Philippa of Lancaster who help to restore normality by their balanced and positive performance. In each of these cases the first element mentioned is dominant on the references. 
Keywords: 1383-1385 dynastic crisis, History of emotions, Fernão Lopes. 


\title{
(
}

\section{O rei que esmorece e a rainha sanhuda: a crise dinástica de 1383-1385 através das emoções nas crónicas de Fernão Lopes / The king that faints and the angry queen: the dynastic crisis of 1383-1385 through emotions in the chronicles of Fernão Lopes}

\author{
Inês Olaia
}

\section{Uma introdução: problemas e conceitos}

A historiografia do Portugal Medieval debateu já amplamente os problemas da transição 1383-1385 sob as mais diferentes perspetivas. Aquilo que aqui trazemos pretende ser apenas um breve estudo centrado no mesmo problema de fundo, mas analisando-o sob uma luz diferente e que nos parece ter sido até aqui ignorada: a das emoções. Olhando cuidadosamente para as crónicas de Fernão Lopes procuraremos estabelecer em que medida as emoções sentidas ou provocadas pelas figuras régias que diretamente influem sobre a ação são manobradas pelo cronista com o intuito de orientar o relato para definir o Mestre de Avis como o melhor candidato ao trono ${ }^{1}$. O nosso foco centrar-se-á sobretudo

\footnotetext{
${ }^{1}$ Estas crónicas servir-nos-ão de fontes, o que não quer dizer que estejam excluídos paralelos com outras. Recenseámos duas versões da crónica de 1344, chamaremos A à mais antiga, e B à mais recente. Utilizaremos as seguintes edições, referenciadas por comodidade como se segue:

- AFONSO, PEDRO (Conde de Barcelos) - Crónica Geral de Espanha de 1344. Reconstituição do ms. L da Crónica Geral de Espanha de 1344 (2. ${ }^{a}$ Parte) de Sílvia Miranda. Lisboa, Faculdade de Letras da Universidade de Lisboa, 2013. Relatório de Estágio de Mestrado. Doravante, 1344 B 2.

- AFONSO, Pedro (Conde de Barcelos) - Crónica Geral de Espanha de 1344. Reconstituição do ms. L da Crónica Geral de Espanha de 1344 (1. a Parte) de Marta Pedrosa. Lisboa: Faculdade de Letras da Universidade de Lisboa, 2013. Relatório de Estágio de Mestrado. Doravante 1344 B 1.

- AFONSO, Pedro (Conde de Barcelos) ou ALFONSO XI - Crónica Geral de Espanha de 1344. Crónica de 1344. Edición crítica y estudio. Vol. II, Ed. Crítica de Ingrid Vindel Perez, Bellaterra: Universitat Autònoma de Barcelona, 2016. Tese de Doutoramento. Disponível em https://ddd.uab.cat/record/167824? 1 =ca Doravante 1344 A.
} 
em Leonor Teles, no Mestre de Avis e em Juan I de Castela, embora não sejam o alvo exclusivo da nossa atenção: como é que Fernão Lopes manobra as emoções sentidas e provocadas por estas figuras e em que medida isso contribui para o desenlace do problema em causa?

Pela sua própria natureza, as crónicas de Fernão Lopes estão desenhadas para serem instrumentos de poder: estão enquadradas num tipo de historiografia promovido pela Coroa, em que o objeto central do discurso é a própria monarquia; agem como promotoras da boa imagem do rei e justificam as suas ações. A cronística medieval portuguesa toma forma no século $\mathrm{XV}$, em estreita proximidade com o contexto político. As crónicas destinavam-se sobretudo a ser lidas e ouvidas na corte, entre os seus oficiais e a alta nobreza.

É precisamente no papel de cronista-mor do reino que encontramos o autor das crónicas que aqui nos ocupam, encomenda do sucessor de D. João I. É natural que o seu texto procure, por todos os meios, legitimar a sucessão invulgar do Mestre de Avis. As crónicas de Fernão Lopes acabam por ser documentos que registam uma versão da história dessa mesma sucessão e utilizam todos os meios para a demonstrar como legítima e benéfica ${ }^{2}$.

Importa-nos definir alguns conceitos essenciais, que nos orientarão o percurso por Fernão Lopes. O mais elementar de todos é o vocábulo "emoção" em si mesmo. Não é fácil de definir e, na verdade, é inexistente na Idade Média. Embora o termo seja mais recente ganhou o sentido atual no final do século XVII -, consagrou-se como nome do campo em

- Crónica de Portugal de 1419. Edição crítica com introdução e notas de Adelino de Almeida Calado. Aveiro: Universidade de Aveiro, 1998. Doravante 1419.

- LOPES, Fernão - Crónica de D. Fernando. Edição Crítica, introdução e índices de Giuliano Macchi. 2. Ed. Revista. Lisboa: Imprensa Nacional-Casa da Moeda, 2004. Doravante CDF.

- LOPES, Fernão - Crónica de D. Pedro. Edição Crítica, introdução e índices de Giuliano Macchi. 2. ${ }^{\mathrm{a}}$ Ed. Revista. Lisboa: Imprensa Nacional-Casa da Moeda, 2007. Doravante CDP.

- LOPES, Fernão - Crónica de Dom João I. Primeira Parte. Edição Crítica e Notas de Teresa Amado, com a colaboração de Ariadne Nunes, Carlota Pimenta e Mário Costa. Lisboa: Imprensa Nacional-Casa da Moeda, 2018. Doravante CDJI.

- LOPES, Fernão - Crónica del Rei Dom Joham I de Boa Memoria e dos Reis de Portugal o Decimo, Parte II. Edição crítica de William J. Entwistle. Lisboa: Imprensa Nacional-Casa da Moeda, 1977. Doravante CDJI-II

2 SOUSA, Bernardo Vasconcelos e - "Medieval Portuguese Royal Chronicles. Topics in a discourse of Identity and Power" in e-Journal of Portuguese History [Em Linha] Vol. 5, n. ${ }^{2} 2$ (2007), [Consultado a 19 abril 2018]. Disponível em http://www.scielo.mec.pt/scielo.php?script=sci_arttext\&pid=S1645$\underline{64322007000200001 \& \operatorname{lng}=p t \& n r m=i s o}$. 
causa e é genericamente aceite assim, conquanto se faça a ressalva necessária. Às portas da modernidade, seriam mais frequentes conceitos como "paixões", "afetos" ou mesmo "sensibilidades", todos eles, de qualquer forma, ligados aos processos físicos do corpo ${ }^{3}$. A ligação é lógica, uma vez que essa visão de proximidade entre corpo e alma era a mais frequente. Não podemos esquecer que as emoções são alvo de tratados e acabam por se ver altamente medicalizadas na viragem do século XIII.

O problema de fundo a que a própria reflexão do período que estudamos nos leva é, no entanto, outro, e um de discussão relativamente recente na medicina e na psicologia: as emoções são características biológicas do ser humano ou construções sociais? Sucintamente, considera-se hoje, fundindo mais que uma teoria, que, embora tenham um fundo biológico, são construções sociais aprendidas, pelo menos na sua forma de expressão e adequação às circunstâncias, através dos códigos sociais em vigor ${ }^{4}$.

Ainda que nos possa ser útil ter uma noção da evolução do campo historiográfico em causa, nos moldes em que se (re)fundou na década de 1980, não compete a este trabalho traçar uma revisão extensa da historiografia e dos diferentes rumos que tomou então ${ }^{5}$. Um dos modelos de análise mais comum está centrado no conceito de comunidade emocional e é-nos aqui útil. Estas comunidades são grupos bem definidos e coesos: por exemplo, um mosteiro, uma confraria ou uma família. Todos podem ser estudados como comunidades sociais, no sentido em que partilham espaços, quotidianos e laços. A história das emoções procura o padrão emocional pelo qual estas se regem. Ou seja, as emoções bem e mal aceites pelo grupo e a forma como o próprio as mostra. O padrão define o que é positivo e o que pode ser perigoso, porque é perante esse tipo de circunstâncias que se expressam

\footnotetext{
${ }^{3}$ BROOMHALL, Susan (ed.) - Early Modern Emotions: An Introduction. Londres: Routledge, 2017, p. 33.

${ }^{4}$ Para uma revisão da ciência por trás das emoções: ROSENWEIN, Barbara H.; CRISTIANI, Riccardo, "Science". in ROSENWEIN, Barbara H.; CRISTIANI, Riccardo - What is the History of Emotions? Cambridge: Polity Press, 2018, pp. 7-25. Para um aprofundamento da perspetiva das emoções como práticas sociais, SCHEER, Monique - "Are emotions a kind of practice (and this is what makes them have history)? A bourdieuian approach to understanding emotion." History and Theory 51 (maio de 2012), pp.193-220.

${ }^{5}$ Para uma introdução à área, ver ROSENWEIN, Barbara H.; CRISTIANI, Riccardo - What is the History of Emotions?...
} 
emoções. A comunidade emocional que aqui nos compete analisar é, portanto, a corte régia $^{6}$. Não somos os primeiros a tomá-la dessa perspetiva ${ }^{7}$.

Na cronística, as emoções funcionam muitas vezes como meio de comunicação. A forma como determinada ação ou evento são recebidos e a reação que provocam, demonstrada depois pelo governante através das emoções, é um claro indicador, para todos os que o rodeiam, da posição a tomar. $\mathrm{O}$ ato é tão deliberado quanto foi, provavelmente, treinado e ponderado na sua educação. Basta recordar o quanto os espelhos de príncipes se focam na boa utilização e controlo das paixões. São estas que estão na base de todos os atos governativos porque são a causa ou revelam a eficácia da ação no discurso do período ${ }^{8}$.

É igualmente no espaço emocional que se jogam as relações entre o vício e a virtude, e o modelo do rei deve ser exemplar nesse âmbito, em simultâneo um homem comum e extraordinário. O ponto essencial é sempre o do equilíbrio. Se a emoção do príncipe for orientada para a virtude, então a decisão consequente será positiva. Caso contrário, o resultado pode ser catastrófico ${ }^{9}$. As emoções são a expressão tangível da persuasão e da ação política, interfaces entre a ação verbal, a ação corporal e a passagem ao ato. Veículo de comunicação entre pessoas de poder, elas marcam as descontinuidades e os eventos políticos; a emoção principesca revela a iminência de um determinado ato ${ }^{10}$.

A nossa análise revelará que, entre os mecanismos que justificam a transição para uma nova dinastia, nas crónicas de Fernão Lopes, contam-se as emoções como a sanha e o medo. O problema da ira régia exige, no entanto, um aprofundamento um pouco diferente. Foi alvo de um número mais amplo de estudos e a sua evolução deu origem inclusive a visões que parecem colidir ${ }^{11}$.

\footnotetext{
6 A definição é de Barbara Rosenwein, citada por LYNCH, Andrew - "Emotional Community". in BROOMHALL, Susan (ed.) - Early Modern Emotions..., p. 3.

${ }^{7}$ Sobre isso, e sobre a opção por "comunidade emocional" e não "regime emocional", BERGQVIST, Kim - "Tears of weakness, tears of love: kings as fathers and sons in medieval Spanish prose". in FÖRNEGÅRD, Per; KIHLMAN, Erika; ÅKESTAM, Mia; ENGWALL, Gunnel - Tears, Sighs and Laughter: Expressions of Emotions in the Middle Ages. Estocolmo: KVHAA, 2017, pp. 82-83.

${ }^{8}$ NAGY, Piroska; BOQUET, Damien - Sensible Moyen Âge. Une histoire des émotions dans l'Occident Medieval. Paris: Seuil, 2015, pp. 229-233.

${ }^{9}$ NAGY, Piroska ; BOQUET, Damien - Sensible Moyen Âge..., pp. 234-235.

${ }^{10}$ NAGY, Piroska ; BOQUET, Damien - Sensible Moyen Âge..., p. 255.

${ }^{11}$ Não exploraremos aprofundadamente essa problemática, por uma questão de economia do discurso. Sinteticamente, o problema está na utilização da ira régia como forma de exercer a justiça ou exercício
} 
O monarca pode expressar a sua mercê e a sua graça através de uma multiplicidade de meios; a ira encontra os mesmos canais ou similares e faz parte da prática de governo (enquanto "rulership", definido por Gerd Althoff nos termos de mecanismo pessoal de regulação, baseado num conjunto de leis não escritas) ${ }^{12}$. A ira também faz, no entanto, parte dos catálogos de pecados medievais, sendo mesmo um pecado mortal. A sua expressão está intrinsecamente ligada ao exercício do poder, porquanto este precisa do terror, do medo, para ser efetivo. Os usos da ira régia mostram, ainda para Althoff, como o ideal cristão de governante coincide ou não com a prática de governo. A paciência, a moderação e a capacidade de perdoar são definidas nos finais da Idade Média como características da própria natureza régia. A ira fornecerá, por fim, um meio de caracterizar monarcas injustos, funcionando como demonstrador da sua incapacidade para governar. Pode ainda ser diametralmente oposta à justiça, o que agrava a caracterização do monarca em causa. Com o correr dos séculos, a ira ganha uma outra conotação, cada vez mais frequente: a ira justa, ou seja, aplicar a ira para alcançar a justiça. A aplicação é possível porque a própria justiça se sobrepõe, em determinados contextos, à clemência. A mudança de paradigma consagra que, no final da Idade Média, a ira régia seja um tópico cada vez mais complexo, porque depende essencialmente do contexto em que é aplicada ${ }^{13}$.

Por sua vez, para Stephen D. White, a ira, nas crónicas, tanto pode ser expressa verbalmente como indicada ou explicitamente mostrada através de ações físicas. É igualmente expressa de forma clara, pública e ritual, codificada para ser compreendida por todos os que a ela assistem. Não se trata, quando lidamos com estas emoções, de uma emoção expressa na intimidade ou vivida com o indivíduo, essa conceção seria um anacronismo. A expressão pública da ira é, normalmente, masculina e feita por aqueles que têm estatuto para tal: reis, nobres... Faz, da mesma forma, parte da ação política e tanto pode ser sua percursora quanto sua consequência; funciona como reconhecimento

arbitrário. Discussão presente em: ORNING, Hans Jacob - "Royal anger between Christian doctrine and practical exigencies". Collegium medievale: interdisciplinary journal of medieval research 22 (2009), pp. 34-54.

12 ALTHOFF, Gerd - "Ira regis: Prolegomena to a history of royal anger". in ROSENWEIN, Barbara H. (ed.) - Anger's past: the social uses of an emotion in the Middle Ages. Ithaca: Cornell University Press, 1998 , p. 59.

${ }^{13}$ Sumariamos aqui as ideias expressas em: ALTHOFF, Gerd - "Ira regis: Prolegomena to a history of royal anger" ..., pp. 61-73. 
legal de determinada ação como reprovável ou injuriosa e aponta os seus autores. Da mesma maneira, a forma como a ira é atenuada tem uma conotação similar ${ }^{14}$.

Enfim, a expressão desta emoção faz claramente parte da discursividade política. É mesmo considerada a emoção régia por excelência, da mesma forma que divina, e surge em consequência de um qualquer ato que desafia a potestas. No final da Idade Média, a ira encontra inclusivamente diversos graus de expressão consoante o que a expressa. Em sentido estrito, responde a uma ofensa, uma desvalorização, em público e injusta, relacionando-se de forma próxima com a honra. Importa, no entanto, sempre, medir a sua expressão, que não seja exagerada ${ }^{15}$.

A ira, por sua vez, inspira medo. Mas medo, temor e receio são três palavras que designam variações do mesmo tema, ou assim parecem, e articulam-se estreitamente com a legitimidade do governo. De facto, parece certo na historiografia que faz parte do governo (rulership) a necessidade de se fazer respeitar e amedrontar (to be feared), incutindo terror no que lhe está subordinado. A ira régia, de que falávamos acima, tem precisamente essa como uma das suas funções ${ }^{16}$.

O medo e a sua relação com a figura régia na Castela do séc. XIV foi já alvo de estudo ${ }^{17}$ e dele partiremos para tentar aduzir algumas ideias que nos podem ser úteis. As Partidas de Alfonso X surgem-nos como ponto de partida. É aí que se encontra a noção fundamental da diferença entre temor e medo. O temor tem a raiz no amor: teme-se, portanto, a quem se deve amar - Deus e o soberano ${ }^{18}$. O medo como tal radica no espanto.

\footnotetext{
${ }^{14}$ Sintetizamos WHITE, Stephen D. - "The politics of anger”. in ROSENWEIN, Barbara - Anger's Past..., pp. 135-149.

${ }^{15}$ NAGY, Piroska; BOQUET, Damien - Sensible Moyen Âge..., pp. 240-241: a ira régia é contida, mas a do senhor feudal retoma diretamente a força guerreira.

${ }^{16}$ ALTHOFF, Gerd - "Ira regis: Prolegomena to a history of royal anger" ..., p. 61. Destacámos três vocábulos, porque contêm em si conceitos de que é difícil encontrar equivalente exato em português. Se "rulership" parece óbvio, "fear" é um caso mais delicado. Como veremos, a diferença entre temor e medo é ténue, mas muito importante neste âmbito. Optámos pelo vocábulo que nos soa mais próximo do original. $\mathrm{O}$ terror destaca-se em itálico porque o autor se refere ao termo latino.

${ }^{17}$ Referimo-nos a FORONDA, François - "El miedo al rey: fuentes e primeras reflexiones acerca de una emoción aristocrática en la Castilla del siglo XIV". e-Spania [Em linha] 4 (dezembro de 2007), [Consultado a 19 abril 2018]. Disponível em https://journals.openedition.org/e-spania/2273.

${ }^{18}$ A relação antagónica entre medo e amor é atestada na versão B da crónica de 1344 B 1 p. 120 e 1344 B 2 p. 196.
} 
E aqui encontramos problemáticas delicadas de tradução e interpretação tanto da bibliografia como das fontes.

O medo, com raiz latina em metus e de que deriva o verbo "amedrontar", e o temor, com origem em timor e de que deriva o verbo "temer", são coisas muito diferentes, embora tendamos a usá-las quase da mesma forma. Por vezes, o medo está relacionado com a proteção da integridade física e da honra daquele que o sofre. Nas crónicas castelhanas, o medo parece funcionar como meio de legitimar e encenar ruturas para depois restabelecer a normalidade a partir de fora, variando na prática com o momento político. É o mesmo artigo de François Foronda que nos chama a atenção para a polarização clássica do poder régio medieval: o polo positivo como rei/amor/temor e o polo negativo tirano/espanto/medo. O uso de qualquer um destes termos pelo cronista Fernão Lopes é delicado: muitas vezes misturam-se e sobrepõem-se. Para complicar, a língua portuguesa junta um terceiro termo a estes dois polos: o receio, que se parece com uma variante mais suave do medo.

A estes dados, podemos ainda juntar um outro: e como é que as mulheres e os homens se distinguem neste campo? Havia uma diferença na perceção e na expressão de emoções entre os dois géneros? A resposta curta é: sim. Quando há mulheres em patamares de poder, estas têm à disposição o mesmo tipo de instrumento de comunicação que qualquer homem. No entanto, parece que a cronística tende a mostrar desagrado quando isso acontece, preferindo reservar-lhes os papéis ditos tradicionais. Em si mesmas, no entanto, as emoções políticas não têm género, mesmo que as mulheres da aristocracia tenham acesso a uma paleta de emoções muito mais restrita. O facto é curioso, tendo em conta que a sociedade medieval faz, das mulheres, seres mais emotivos por natureza ${ }^{19}$.

\section{A sanha, o amor e o desequilíbrio: Leonor e Fernando}

No final da Idade Média, a teorização política apresenta-se muito ligada à metáfora do corpo: transpõe a visão teológica da Igreja como corpo místico de Cristo, ligando assim o rei ao reino como Cristo à Igreja. A conceção orgânica e pessoal do governo coloca a compleição e o temperamento do monarca sob escrutínio, tal como a sua relação com o

\footnotetext{
${ }^{19}$ NAGY, Piroska; BOQUET, Damien - Sensible Moyen Âge..., p. 255.
} 
corpo que é o reino. Ao coração dá-se um particular destaque, definindo-se pelo lugar das emoções o próprio monarca ${ }^{20}$. Foi aí, no coração, que a medicina florescente nos séculos XII-XIII localizou as emoções. Na verdade, chega mesmo a considerar-se que as emoções são os movimentos da alma, que se manifestam somaticamente no coração. À luz do tempo, portanto, todas as emoções sem exceção por lá passam ${ }^{21}$. E que dizer do tamanho do coração de um grande senhor? Numa crónica em que as referências ao coração se multiplicam, o de Leonor Teles surge definido como grande, justificando as suas ações/emoções fora do comum ${ }^{22}$, e caracterizado como "vingador" ${ }^{23}$. Em qualquer uma das crónicas que falamos, as emoções da rainha parecem muitas vezes excessivas, desregradas ou mal ritualizadas. Mas se assim é, aquelas que o rei D. Fernando expressa por ela estão em patamar similar.

Por tudo o que expusemos, é lógico que a ira seja uma das emoções mais amplamente expressas na generalidade. A surpresa surge quando, analisando a Crónica de D. João I, é a rainha Leonor Teles que domina as referências à sanha em toda a Primeira Parte, quer seja porque a emoção é sentida e expressa por ela, quer esteja apenas no seu entorno direto. Sofre- $\mathrm{a}^{24}$ e a ela ninguém podia fazer nojo, porque sofreria rapidamente a sua sanha. Esta consideração de Fernão Lopes obriga-nos a retomar a necessidade de a ira régia ser moderada. O desregramento que aponta a Leonor Teles é mais um fator que contribui para justificar a sua queda. Notemos que Fernão Lopes equipara, na primeira ocasião que citámos, o ódio que pede vingança ao amor que não descansa enquanto não alcança quem quer. Em ambos a rainha se viu ou vê enredada. A ira implica, diretamente, a emoção seguinte que aqui abordamos na relação com Leonor Teles: o medo.

Se é a mais sanhuda das personagens, Leonor Teles tem ainda a particularidade de, nas crónicas de Fernão Lopes, ser o caso único de uma mulher que sente medo e o inspira. No caso das menções em volta desta rainha, é particularmente importante analisar a evolução da utilização destes termos e daí extrair algumas conclusões possíveis. Começamos por a ver com temor depois da morte de Andeiro $^{25}$ e com o mesmo

\footnotetext{
${ }^{20}$ NAGY, Piroska ; BOQUET, Damien - Sensible Moyen Âge..., pp. 226-227.

${ }^{21}$ NAGY, Piroska ; BOQUET, Damien - Sensible Moyen Âge..., p. 195.

${ }^{22}$ CDJI p. 155 e p. 144 , p. ex.; "grandioso coraçom de que natureza lhe nom fora escassa" p. 57.

${ }^{23}$ CDJI p. 53.

${ }^{24}$ CDJI p. 57, que motiva uma longa reflexão do cronista e p.127, embora não muito claramente.

${ }^{25}$ CDJI p. 38. É a medo, no entanto, que outros falam com o Mestre.
} 
sentimento se refugia em Alenquer ${ }^{26}$. Mas, ao escrever ao rei de Castela, o cronista já não diz que Leonor Teles tem temor do povo de Lisboa, mas receio ${ }^{27}$. É sem medo nem receio que a rainha se apresenta perante o rei de Castela, estando já presa ${ }^{28}$. Portanto, o vocabulário escala de temor a medo, para um final, quando a situação é irremediável, sem emoção associada.

Mencionadas as emoções que a rainha sente, passamos agora às que ela provoca. É com temor da rainha que o povo procura fazer o Mestre ficar no reino. Mas rapidamente já não é só temor: é com medrosos pensamentos que se encontram ${ }^{29}$. O temor deixa as gentes quando D. João decide ficar ${ }^{30}$. E é, por fim, com receio da rainha, depois do que sucedera aquando do seu casamento, que os grandes da cidade de Lisboa hesitam em tomar D. João como regedor ${ }^{31}$. Se notarmos bem, o vocabulário escalou um pouco: passámos de temor - devido sempre ao senhor natural - a receio, que em português caminha perto do medo, com um desvio subtil até "pensamentos medrosos", pelo meio.

Sobre as emoções que a rainha provoca a Lisboa, a impressão é a de que há uma mudança palpável: se, primeiro, Leonor Teles inspira temor, esse temor balança-se junto ao medo, caminhando perigosamente perto do que é inaceitável, porque o medo está ligado à tirania. Em fuga à emoção, o povo de Lisboa escolhe o Mestre de Avis para regedor, não sem hesitações. Esta é uma consideração frágil, por tudo o que dissemos até aqui: as palavras têm sentidos de fundo diferentes que conseguimos, de facto, detetar, mas não deixam de se sobrepor pela proximidade dos conceitos e a sinonímia que permitem. Não obstante, parece uma evolução óbvia e lógica e que é preciso realçar. O afastamento de D. Leonor da regência tem, não só, mas igualmente, motivação no campo das emoções, em estreita relação com a teoria política e a oposição entre o tirano e o senhor natural.

Da mesma forma, se considerarmos, como Susan Broomhall ${ }^{32}$, que a autoridade implica a existência de um ascendente sobre quem é exercida e que pode emergir por si própria e

\footnotetext{
${ }^{26}$ CDJI p. 51.

${ }^{27}$ CDJI p. 121.

${ }^{28}$ CDJI p. 155.

${ }^{29}$ CDJI p. 54.

${ }^{30}$ CDJI p. 64.

${ }^{31}$ CDJI p. 65.

${ }^{32}$ BROOMHALL, Susan - "Introduction: Authority, Gender and Emotions in Late Medieval England". In BROOMHALL, Susan - Authority, Gender and Emotions in Late Medieval England. Nova Iorque: Palgrave Macmillan, 2015, pp. 1-17.
} 
criar poder, o desenho começa a tornar-se mais claro. O poder pode ser facilmente retirado por simples exercício da força ou um qualquer golpe, enquanto a autoridade, mais vasta, exige sistematicamente a sua própria renovação através da circulação quotidiana de poder expressa em ações concretas. A ritualização das emoções pode contar-se entre estas: o desempenho dessas ações por Leonor Teles está minado pelo cronista. Se, primeiro, Fernão Lopes parece implicitamente aproximá-la da tirania, se analisarmos um segundo caso, o dó, é claramente visível a incapacidade que o cronista lhe imputa na expressividade das suas emoções.

De outra perspetiva, o afastamento de D. Leonor da regência pode ser descrito como um desafio malsucedido a um regime emocional. Simon Doubleday considerou, a propósito da ira na Crónica de Alfonso $X$, que a forma como o rei a utiliza, contendo-a e expressando-a em ocasiões diferentes, pode ser uma marca de um regime emocional. $\mathrm{O}$ conceito foi descrito por William M. Redy ${ }^{33}$ e adequa-se na medida em que é visível na crónica um "sistema de sentir" em ação. Isto é, uma maneira de expressar emoções, imposta do centro de poder para as margens. Muitas vezes, quando esse sistema é desafiado, gera-se uma mudança política ${ }^{34}$.

É no mesmo capítulo em que explica como é que Leonor Teles se tornou "regedor do reino" que o cronista aponta a falsidade do seu luto por D. Fernando, o que poderá não ser inocente. Claramente fingido, para Fernão Lopes, é o luto que a rainha faz questão de mostrar quando recebe alguém no paço depois da morte de D. Fernando ${ }^{35}$, o que naturalmente destrói um pouco mais a sua imagem. O problema do luto pelo monarca estende-se pela primeira parte da Crónica de D. João I. O luto pelo rei, ainda que altamente ritualizado pela rainha (o espaço reservado onde se encontra ${ }^{36}$, o estar coberta de dó de forma habitual ${ }^{37}$, apresentar-se ao rei de Castela e a D. Beatriz de rosto velado e manto preto $^{38}$ ) contrasta dramaticamente com as suas ações. Quem a repreende é o rei de

\footnotetext{
${ }^{33} \mathrm{O}$ trabalho fundamental do autor, onde explica a teoria: REDDY, William M. - The Navigation of Feeling. A Framework for the History of Emotions. New York, 2001.

${ }^{34}$ DOUBLEDAY, Simon - "Anger in the Cronica de Alfonso X”. in Al-Masaqol Vol. 27, n. ${ }^{\circ} 1$ (2015), p. 62. Da mesma maneira, em Inglaterra, as acusações de desequilíbrio emocional servem para minar a autoridade régia - p. 68 .

${ }^{35}$ CDF p. 594.

${ }^{36}$ CDJI p. 35.

${ }^{37}$ CDJI p. 45.

${ }^{38}$ CDJI p.125, que pode ou não ser luto, mas contribui para o peso dramático.
} 
Castela, porque fala de mais e de forma demasiado desprendida para uma viúva tão recente e coberta de dó. Essa é, precisamente, a primeira razão para o "desprazer” de Juan I de Castela. Mais uma vez, a rainha falha, de forma gritante, na apresentação pública das suas emoções ${ }^{39}$.

A ideia de um luto fingido já é anterior ao falecimento de D. Fernando: a primeira referência ao dó de Leonor Teles surge a propósito do desenlace da trama tecida em torno de D. Maria Teles e do infante D. João, que culmina no assassinato da própria irmã da rainha por um meio-irmão do rei, que se exila em Castela. Não só o dó que a rainha mostra é alvo de insinuação por Fernão Lopes (o mostrar que algo lhe pesa não parece ser o mesmo que dizer apenas que pesa) como é contraditado pela própria: coloca dó, mas insiste com o rei que não se importe com o assunto, afirmando-o banal. Esta ritualização encenada de uma emoção falseada por Leonor Teles aparece noutro ponto na Crónica de D. Fernando: é isso que parece indicar o cronista quando diz que a rainha chorava, parecia que com saudades da filha, Beatriz, ao despedir-se dela quando a criança casou ${ }^{40}$. Seria lógico que sentisse saudades e chorasse a partida de Beatriz, a julgar, por exemplo, pelo cenário semelhante traçado pela crónica de 1419 em torno da partida de Isabel de Aragão de junto do pai, Pedro de Aragão ${ }^{41}$. No entanto, novamente, o cronista avisino deixa no ar a insinuação de que "parece", o que é, claro, diferente de sentir, de facto. Fernão Lopes estaria, já, apostado em criar uma determinada imagem negativa para a rainha e serve-se, nesta perspetiva, da falsidade com que apresenta as suas emoções ${ }^{42}$.

Retomando as noções de autoridade e poder explanadas, percecionamos que a rainha tem poder quando chega o momento da regência, porque tal lhe foi entregue através do tratado de Salvaterra, mas a sua autoridade está minada. O falhanço na ritualização das emoções adjacentes à morte de D. Fernando (emoções que ela não sente, para Fernão Lopes) contribui para essa mesma perda, uma vez que elimina uma das variáveis (as emoções e os respetivos mecanismos de comunicação) que contribuem para a sustentação da autoridade. A perda do poder em si mesmo pela rainha seria apenas uma questão de

\footnotetext{
${ }^{39}$ CDJI p. 145.

${ }^{40}$ CDF p. 572.

${ }^{41} 1419$ p. 165.

${ }^{42}$ CDF p. 375.
} 
tempo. Mas nem todos os males se podem atribuir a Leonor Teles. O desregramento emocional de D. Fernando contribuiu para o final da história em causa.

Vejamos, então, o que diz Fernão Lopes sobre o apaixonado monarca. O cronista preparanos logo na abertura da crónica dedicada ao seu reinado, dizendo que era "ledo e namorado, amador de mulheres e achegador a elas"; "amavioso de todollos que com elle viviam"43. Este tipo de caracterização prepara-nos para o que se segue e quase parece abrir caminho para uma caracterização "emocional" algo instável, o que não é positivo. Quando chegamos ao amor de D. Fernando por Leonor Teles, o caso torna-se deveras interessante. Da instabilidade - ou excesso? - dos amores do rei, dá o cronista notícia quando conta que ponderara casar com a própria meia-irmã, Beatriz, tendo com ela gestos um pouco atentatórios ao seu pudor e bom nome ${ }^{44}$. Colocar estas informações sobre a sua hipotética paixão pela meia-irmã no capítulo em que se propõe contar como é que o monarca se apaixonara por Leonor Teles é, no mínimo, suspeito, mesmo verificando que a ligação à futura rainha se faz porque esta se trata de um membro da casa de D. Beatriz.

D. Fernando rapidamente se perde de amores - palavra de cronista - e nada nem ninguém lhe tira da cabeça Leonor Teles. É uma chaga no seu coração, o que por si só nos encaminha para noção de mal/doença física ${ }^{45}$. A estranheza do casamento surge nos fidalgos que amavam o serviço do rei, juntando assim dois tipos de amor: o do vassalo para com o senhor e a paixão ${ }^{46}$. As considerações que Fernão Lopes tece em seguida, sobre os homens "namorados" como estava o rei, davam-nos para todo um outro estudo. É no capítulo LXIII da crónica que as encontramos. Indica o cronista que diziam que "todo homem namorado tem hua especia de sandice", por duas razões: primeiro porque o mesmo que leva à loucura nalguns casos está presente nestes; segundo porque a "virtude extimativa" (a capacidade de discernir corretamente?), que é quem governa a alma nestas coisas, está doente nos homens na situação de D. Fernando, toldando o raciocínio a tal

\footnotetext{
${ }^{43}$ CDF p. 3. O facto de amar todos os que com ele viviam podia ser um sinal positivo: o amor, neste contexto, pode ser o laço que une o vassalo e o senhor, como mostramos atrás. É a insistência do cronista que queremos reforçar.

${ }^{44}$ CDF p. 198. Além dos constantes momentos partilhados, beijos e abraços são sinal afetivo. O mesmo serve para desfazer o casamento da filha ilegítima de D. Fernando: CDF p. 337.

${ }^{45}$ CDF pp. 199-200.

${ }^{46}$ CDF p. 209.
} 
ponto que o feio parece bonito e o mau bom, por isso não ouve ninguém que lhe diga para se afastar da mulher que o provoca.

No substrato do que diz Fernão Lopes, encontramos a razão como senhora absoluta, subjugando a vontade, como se lê no Leal Conselheiro, da pena de D. Duarte ${ }^{47}$. Nada de estranho, tendo em conta a proximidade dos dois autores. A caracterização negativa de D. Fernando corresponde de forma precisa ao contrário desse padrão ideal.

Portanto, o amor, a paixão fulminante, faz adoecer a razão, o que se enquadra perfeitamente no quanto as emoções desregradas são negativas. Quando se fala deste tipo de amor, normalmente as mulheres são o seu alvo e isso pode dar-lhes um imenso poder: o cronista acusa D. Leonor de manipular o rei em ocasiões diversas, tal como a irmã, Maria Teles, foi capaz de manipular D. João para com ela se casar ${ }^{48}$. Em última instância, é o desregramento emocional de D. Fernando que ajuda a precipitar o reino no caos que se segue ao seu reinado.

Mas o amor das crónicas não é, sempre, o amor da paixão. Há um outro tipo de amor por trás das ações de Leonor Teles: aquele que os vassalos devem ao seu senhor. É essa a justificação que Fernão Lopes apresenta para a trama desenhada em torno do par Infante D. João-Maria Teles. Porque o povo o amava tanto como ao rei (e assim Maria Teles estaria no lugar equivalente ao da própria rainha) e dificilmente isso não representaria um perigo para a coroa ${ }^{49}$.

Acresce a tudo o que dissemos sobre a caracterização da rainha D. Leonor uma ressalva: é mulher. E se isso não parece muito, a sua sanha é um contraste alarmante com a absoluta serenidade com que Isabel de Aragão é representada noutra crónica coeva ${ }^{50}$. Portanto, a sanha é admissível ao rei, na medida em que é contrabalançada pela justiça ou aplacada por alguém adequado. À rainha, talvez não seja, simplesmente. E nunca saberemos que diria Fernão Lopes de uma rainha-reinante em vez de consorte. Da mesma forma, o dó parece ser sistematicamente atribuído às mulheres pelo cronista, quando o define como

\footnotetext{
${ }^{47}$ Sobre este assunto, BERLIN, Henry - "The willing reader of Duarte's Leal Conselheiro". in Journal of Medieval Iberian Studies Vol. 5, n. ${ }^{2} 2$ (2013), pp. 204-219.

${ }^{48}$ CDF pp. 357-359.

${ }^{49}$ CDF p. 361.

${ }^{50} 1419$ p. 166.
} 
tal. Talvez por isso mesmo, o comportamento de Leonor Teles seja na sua redação tão desadequado. Acresce a isto a acusação de que as mulheres são capazes de facilmente falsear emoções para atingirem os seus intentos. A ideia é expressa no relato do casamento escondido de Maria Teles e do Infante D. João ${ }^{51}$.

\section{Medo, choro, dó: Juan I e Beatriz}

As emoções associadas pela crónica de D. João I aos reis de Castela são, em regra, negativas, o que não é estranho: são precisamente os castelhanos que Fernão Lopes combate durante grande parte da crónica. É preciso deslegitimar a sua pretensão ao trono português de todas as formas possíveis. É interessante notar, por exemplo, que do rei de Castela só se tem uma coisa em Portugal: medo. Não é temor, nem receio. É medo, o que só por si é grave porque remete, por tudo o que dissemos, à injustiça e à tirania, e sustenta, de uma outra forma, a ilegitimidade com que tenta segurar a coroa portuguesa ${ }^{52}$.

Por outro lado, na senda de encontrar todos os meios para afastar Juan I de Portugal, Fernão Lopes utiliza o coração, o lugar privilegiado da emoção, para colocar uma advertência na boca de Pero Fernandes de Velasco, perante a armada portuguesa à vista de Lisboa, estando prestes a defrontar-se com a castelhana: mesmo que consiga ganhar a batalha, jamais conseguirá os corações e o amor do povo ${ }^{53}$. A ligação entre o senhor natural e o amor é mais uma vez afastada das possibilidades de Juan I de Castela. É, por fim, com tristeza que Juan I de Castela parte depois de descercar Lisboa ${ }^{54}$.

A batalha de Aljubarrota e as suas consequências, tal como é relatada pela primeira parte da Crónica de D. João I, seriam motivo para todo o tipo de considerações a este nível. Em contexto de guerra, o medo é presença frequente, não tanto por questões de natureza política, mas numa outra dicotomia, que Fernão Lopes aplica com frequência: o medo, em relação estreita com a proteção física e o perigo. O espanto, estádio imediatamente anterior e próximo do que hoje chamamos susto, surge nas imediações da batalha, porque é isso que a comitiva de Juan I de Castela provoca $^{55}$ e o mesmo se diz que a multidão do

\footnotetext{
${ }^{51}$ CDF p. 358.

${ }^{52}$ CDJI p. 159.

${ }^{53}$ CDJI p. 236.

${ }^{54}$ CDJI p. 286. A tristeza não é uma emoção encontrada com frequência.

${ }^{55}$ CDJI-II p. 69.
} 
exército frente aos portugueses gera ${ }^{56}$, sendo mesmo o que os trons castelhanos querem suscitar ${ }^{57}$. A consequência imediata é a da elevação dos guerreiros portugueses, que vencem o medo e saem exaltados da cena.

No final da batalha, a derrota é marcada pelas lágrimas de Juan I de Castela. O episódio mistura tristeza, sinais de dó, um quase desmaio e uma repreensão. Perdida a batalha e caída a noite (noite que, noutro lugar da crónica, é escura, é triste) ${ }^{58}$, Juan I de Castela abandona Aljubarrota e cavalga, sem parar a não ser para trocar de montada, até Santarém. Chega quase só à vila; a cena é tão estranha que quem tem a responsabilidade de abrir a porta do castelo duvida que seja o rei que está à porta, é preciso o próprio identificar-se. Juan I de Castela apresenta-se de rosto coberto, não sabemos se traz ainda a armadura ou outra peça. Está triste, visivelmente. Fala sozinho, repreendendo-se e maldizendo a sua sorte. De frente para uma parede, dá palmadas no seu próprio rosto - o que nos recorda os gestos próprios das cenas de dó - e chora, depois, com a cabeça encostada à parede. Quando termina e se volta para os que o observam, parece-lhes que "esmorece" (desmaia?), sendo amparado por eles.

O rei crê mesmo que perdeu todos os que consigo estavam na batalha, o que justifica o seu desespero: não só foi derrotado como perdeu a fina flor da aristocracia. O momento termina com o rei comendo uma sopa que pedira que lhe aquecessem. Segue-se uma pesada repreensão do responsável pela alcáçova de Santarém: Juan I de Castela não é o primeiro senhor a sofrer uma derrota, a tristeza não the traz a vingança, e o exemplo do pai - que mesmo perdendo nunca "perdeu coraçom" - tem de lhe servir. A resposta de Juan I de Castela vem com escárnio e palavras que recordam a sua imensa desonra por ter perdido assim. Fernão Lopes prossegue insinuando que é com medo que Juan I de Castela parte de Santarém, ainda de noite, para Lisboa pelo rio com o rosto coberto. De Lisboa segue para Sevilha, só no dia 17, onde chega de noite, para evitar o clamor e “choro das gentes". A população, ao saber, reage em pranto e o rei, atingido pela tristeza e nojo, parte para Carmona. Juan I de Castela veste-se completamente de preto, da roupa às divisões onde se encontra ${ }^{59}$.

\footnotetext{
${ }^{56}$ CDJI-II p. 95.

${ }^{57}$ CDJI-II p. 96.

${ }^{58}$ CDJI p. 318.

${ }^{59}$ CDJI-II pp 100-103.
} 
Embora Fernão Lopes nunca o diga, é de dó a cena que compõe para mostrar a reação do rei de Castela à derrota. Os sinais típicos estão todos presentes, até ao excesso: o choro, o próprio rosto agredido, inclusive o ato de maldizer a sua própria sorte. O episódio recorda, com alguma semelhança, a reação do rei Rodrigo à derrota face às forças muçulmanas, embora este último não seja alvo de uma reprimenda ${ }^{60}$; rei repreendido pela tristeza face a uma derrota militar é D. Fernando de Portugal ${ }^{61}$, e quem o repreende é Leonor Teles, no único momento em que o cronista se permite uma palavra positiva quanto à rainha.

Não é comum encontrar nas crónicas cenas de dó em que os homens intervenham e nenhum rei faz "dó" para o cronista, mesmo que chore a perda de alguém ${ }^{62}$. Em regra, independentemente da crónica, são as mulheres as "encarregadas" desses gestos rituais e apenas quando é necessário acentuar determinado momento de dó, o cronista insere homens nesse contexto. O exagero dos atos do dó pode levar mesmo ao desmaio das envolvidas $^{63}$, o que acentua igualmente o carácter da situação descrita a propósito da derrota em Aljubarrota.

Por outro lado, os desmaios femininos ocorrem frequentemente quando as mulheres das crónicas sofrem um choque emocional forte. Fernão Lopes introduz uma nuance de género: Juan I de Castela "parece esmorecer", não levando, portanto, ao extremo o episódio que relata. Ao saber da mesma notícia, Beatriz de Portugal "cayo em terra assy como morta" ${ }^{64}$, seguindo-se sobre ela o pranto das damas que a acompanham. Todas estas referências contribuem para reforçar a carga da derrota, por um lado, e a impressão da vitória esmagadora e inesperada das forças portuguesas.

\section{O equilíbrio, a justiça e a alegria: João e Filipa}

O retrato que Fernão Lopes nos oferece no prólogo da segunda parte da Crónica de D. João I, está desenhado para nos mostrar as qualidades de um bom rei. Entre elas está a ponderação e o equilíbrio das paixões. D. João I é retratado como equilibrado; ser

\footnotetext{
${ }^{60} 1344$ A p. 1211344 B 1 p. 268.

${ }^{61}$ CDF p. 448.

${ }^{62}$ CDF p. 3; CDJI-II p. 231.

631344 A p. 492, a título de exemplo.

${ }^{64}$ CDJI-II p. 103.
} 
demasiado "sanhudo" é sinal de instabilidade e gerador de problemas. O rei é tido como não sendo sanhudo nem cruel, mas manso e benigno a castigar ${ }^{65}$. O longo prólogo, depois de tecer rasgados elogios às virtudes do monarca, conclui que era grande distribuidor de mercês e que é por isso que todos o querem amar e servir ${ }^{66}$. As poucas vezes que surge irado, em ambas as partes da crónica, têm propósitos concretos ou estão perfeitamente justificadas.

A primeira vez que tal acontece ainda é, apenas, o defensor e regedor do reino. Portanto, poder-se-ia dizer que a sua ira não é régia, porque, factualmente, ainda não é rei. Mas Fernão Lopes desenhou-o para o ser, desde a Crónica de D. Pedro I; e, efetivamente, o lugar que ocupa coloca-o perto. A sua ira é dura e implacável quando se sente traído ${ }^{67}$. Apenas uma vez encontramos D. João, Mestre de Avis, a inspirar medo, depreende-se pelo episódio que se trate de uma explosão da sua ira a causa. Mas a culpa não é dele.

Cercava-se o castelo da vila de Torres Vedras, fiel a Castela. Acontece que, durante o cerco, todas as hipóteses que D. João I apontava para entrar na fortaleza estavam goradas à partida porque o estavam a trair. Num desses casos, o regedor e defensor do reino mandara as catapultas lançarem à muralha do castelo, com o fito de derrubar parte dela $\mathrm{e}$ assim entrar. A ordem que chega a quem as manobra é contrária: que se lance às torres. Um dos oficiais, desconfiado, resolve misturar a ordem que recebera com aquilo que o bom senso the diz e que coincide com a ordem inicial de D. João. Por azar, o Mestre descobre o oficial a lançar às torres e enfurece-se; ameaça atirá-lo para dentro da vila se não cumprir a sua ordem (que, recordemos, o homem não recebera originalmente, mas inadvertidamente tentava cumprir). O oficial, assustado (e provavelmente confuso, dizemos nós) foge dali para Leiria ${ }^{68}$.

Medo (e o seu estádio imediatamente anterior, o espanto) é algo que D. João I é capaz de infligir, seguramente, em Leonor Teles e no seu entorno... Em sentido inverso, é capaz de retirar do espectro do medo o povo de Lisboa, intimidado pela rainha. Se em Castela

\footnotetext{
${ }^{65}$ CDJI-II p.2.

${ }^{66} \mathrm{CDJI}$ - II, p. 3.

${ }^{67}$ CDJI p. 340.

${ }^{68}$ CDJI p. 326.
} 
o medo serve para encenar ruturas políticas na cronística, o mesmo parece ser possível dizer sobre Portugal na crise dinástica de 1383-1385.

Sanha sem medida, mas sempre mediada pela justiça e no caminho dos bons costumes portanto, a ira do bom rei e bem aplicada -, encontramos em D. João I uma vez: quando o camareiro Fernando Afonso é "apanhado" com Beatriz de Castro. A ira régia não conhece barreiras, neste caso: sabendo que aquele escapara ao corregedor, o rei sai do Paço a meio da sesta, mal vestido e mal acompanhado, e dirige-se à igreja. Quando finalmente a porta se abre ao rei, o prevaricador desce do coro e agarra-se a uma imagem da Virgem no altar-mor. Arrancado ao altar, arrasta consigo a imagem. Nem a artimanha montada para escapar à sanha do rei (dizerem-se marido e mulher, Fernando e Beatriz), nem qualquer fidalgo ou mesmo a rainha valem ao camareiro. É morto, queimado em praça pública, uma condenação infame ${ }^{69}$.

As crónicas que analisámos detêm-se, em regra, no amor, em três circunstâncias: as relações entre o senhor e os vassalos, a diplomacia e a paixão. A crónica de D. João I assinala, no entanto, mais uma forma quase indetetável nos outros textos: as relações familiares. Se não há dúvida de que o rei será retratado como um soberano amado ${ }^{70}$, acresce a esta a relação no sentido inverso: D. João é escolhido para rei em Coimbra porque, entre muitas outras coisas, mostrou amor aos súbditos ${ }^{71}$.

O amor familiar e a exemplar relação entre os infantes da Ínclita Geração e o pai são exaltados na crónica de forma altamente elogiosa e por demais conhecida. O cronista aposta, até, no contraste com os pares infante Afonso-D. Dinis e infante Pedro-Afonso IV, para insistir na diferença maior: a obediência ${ }^{72}$. A perfeição dos infantes é expressa por Fernão Lopes em termos que não nos atrevemos a parafrasear:

“ouueram tal conhecimento de seus preçeytos e mandados [de Deus], que conformes a elles, sem outra mudança, com gramde amor e themor e fee leal

\footnotetext{
${ }^{69}$ CDJI-II p. 286.

${ }^{70}$ Atente-se, por exemplo, nas festas do seu acolhimento no Porto.

${ }^{71}$ CJI p. 374.

${ }^{72}$ CDJI-II p. 308.
} 
nenhuma coisa vergonhossa ou de repremder fezerão, per que el-Rey seu padre somente huma ora dalguum deles fosse anojado"73.

O temor deriva do amor e, portanto, está no espectro positivo do medo: porque se amam os pais, o soberano, não se quer desagradar-lhes, há medo em perder o seu amor ou maculá-lo. Seguem-se a vergonha e o nojo. À luz da nossa leitura, a caracterização do cronista não podia fazer esses filhos mais perfeitos: o amor ao pai e o temor daí decorrente, a vergonha inexistente que os eleva nos patamares da honra, o pai que nunca com eles sente nojo (desprazer). O cronista prossegue em termos semelhantes: os infantes nunca mostravam o quanto o pai lhes podia desagradar, nem com gestos tristes (o que, sabemos, não deveria ser verdade $)^{74}$. O modelo dos filhos sempre agradando e apoiando o pai domina todo o capítulo ${ }^{75}$.

A propósito de amor, dissemos igualmente que Fernão Lopes coloca em D. Fernando um imenso desregramento e que isso conduz o reino ao caos de que emerge D. João I. Não é surpreendente, portanto, que o cronista utilize a relação conjugal para estabelecer a imensa diferença entre os últimos monarcas de Borgonha e os primeiros Avis. Para haver amor entre um casal é preciso equilíbrio e não se deixar governar por ele, como em tudo. Assim nos conta Fernão Lopes: D. João I "Homrou muyto e amou sua molher de honesto e saão amor", nunca tendo cedido à rainha nos feitos de justiça. Extraordinário contraste, portanto, com o casal anterior ${ }^{76}$.

De tudo o que até agora dissemos, falámos apenas de profundas tristezas, de fúrias e de amor. Então, e a alegria, a ledice? Pois bem, só a encontramos com expressão significativa com este rei, embora surja esporadicamente associada a outras figuras ${ }^{77}$. No entorno de D. João tem outros sentidos: é ledos que ficam os povos quando o Mestre aceita ser regedor e rei, e é com muita ledice que os guerreiros aguardam, por exemplo, a Batalha de Aljubarrota ${ }^{78}$. O paralelo com Afonso Henriques, alçado por rei na Crónica de

\footnotetext{
${ }^{73} \mathrm{O}$ capítulo é de alto interesse para este contexto: CDJI-II pp. 310-311.

${ }^{74}$ CDJI-II p. 309.

${ }^{75}$ CDJI-II pp. $310-311$.

${ }^{76} \mathrm{CDJI}-$ II p. 3.

77 Tanto a caracterização de D. Fernando (CDF p. 3) como a do infante D. João (CDF p. 355) remetem para a ledice, o que pode ser um mecanismo intencional, dado o desenlace da história de ambos.

${ }^{78}$ CDJI-II p. 86.
} 
Portugal 1419, com a "alegria e prazer" dos seus companheiros, é irresistível ${ }^{79}$. Pelas razões óbvias, a alegria que rodeia a chegada de D. João I ao Porto e o seu casamento são evidentes; assim como é dançando (alegre!) que Antão Vasques entrega a bandeira de Castela capturada em Aljubarrota ao rei $^{80}$. A alegria rodeia o futuro rei desde cedo, na verdade: o pai, D. Pedro, é retratado alegre, na crónica que lhe é dedicada apenas duas vezes. A primeira, quando dança pelas ruas a altas horas da noite ${ }^{81}$. O cronista deixa no ar a ideia de que o rei raramente era visto tão ledo (embora fosse ledo em dar ${ }^{82}$ e fazer justiça ${ }^{83}$ ), dada a alegria do povo em vê-lo assim. A segunda ocasião acontece quando se arma cavaleiro o filho mais novo, D. João ${ }^{84}$.

Em suma, o casal régio D. João I e D. Filipa é apresentado como bom modelo. Provocam sentimentos positivos em todos os que os rodeiam e mesmo quando o próprio D. João I expressa emoções negativas, elas são plenamente justificadas pelo cronista no contexto em causa e raramente quebram a barreira do que é aceitável ${ }^{85}$.

\section{Conclusão}

Por tudo o que expusemos, a conclusão natural é a de que as emoções que circundam as figuras régias que acompanhámos nas crónicas de Fernão Lopes funcionam como meio de legitimação da mudança dinástica de 1385. E isso mesmo acontece em duas medidas: ou são um dos mecanismos que suporta o desenrolar da ação ou apoiam a caracterização de uma determinada figura no sentido de a capacitar ou incapacitar para o lugar que ocupa ou pretende ocupar.

Não é uma surpresa que seja assim, na esteira da história que o cronista está a desenhar. Como vimos, já se concluiu para Castela que o medo na cronística serve para encenar e justificar mudanças; o mesmo se poderá dizer para o caso da crise dinástica de 1383-1385.

\footnotetext{
791419 p. 22.

${ }^{80}$ CDJI-II p. 107.

${ }^{81}$ CDP p. 60.

${ }^{82}$ CDP p. 8 e p. 47.

${ }^{83}$ CDP p. 27.

${ }^{84}$ CDP p. 191.

${ }^{85}$ BERGQVIST, Kim - "Tears of weakness, tears of love: kings as fathers and sons in medieval Spanish prose" ..., p. 89 explica como a moderação ao nível das emoções é já teorizada por Alfonso X.
} 
Com fatores tão subtis como esse mesmo medo, o cronista abeira-se de temas tão imensos como a definição de um bom ou mau rei, através da aproximação ou afastamento da imagem do tirano.

Fernão Lopes exalta, por outro lado, as façanhas dos portugueses mostrando o desespero que o seu desempenho despoleta no entorno castelhano. Para isso, utiliza mecanismos como o dó. O desespero de Juan I de Castela, depois de perdida a batalha de Aljubarrota, é exemplar. Os exageros que o cronista imputa ao rei castelhano têm paralelo difícil nas restantes crónicas que nos chegaram do mesmo autor.

São diversas as variáveis que aqui encontramos. O cronista está claramente a colar emoções negativas e desregradas às figuras que pretende mostrar dessa maneira, o que não é uma surpresa. Pode não constituir surpresa igualmente o facto de estes textos parecerem fazer com que certas figuras, que têm um papel negativo no relato, quebrem fronteiras de género. Isso mesmo parece acontecer com Leonor Teles, que exibe uma sanha suficiente para assustar: nem a sanha desmedida era uma coisa positiva, nem a sanha feminina seria vista com bons olhos. O mesmo sucede com o desespero de Juan I de Castela após a derrota de Aljubarrota, que exibe um comportamento típico de atos de dó que Fernão Lopes dificilmente imputa a mais alguém e só atribui com relativa semelhança a mulheres. Compreender como o cronista desenha o texto, os tópicos e os mecanismos que utiliza, pode lançar um pouco mais de luz sobre a comunicação política da época e os diferentes sentires e expressares das emoções no Portugal Medieval.

A história que Fernão Lopes conta tem de ser, sobretudo, verosímil e adequar-se à memória dos que viveram os factos, sob pena de não ser aceite. Mas o cronista não deixa de ser o cronista régio, com o dever de ajudar a fortalecer uma dinastia que acabava de chegar ao poder. A forma como contou a história da crise dinástica de 1383-1385 usou claramente as emoções de acordo com aquilo que a comunidade emocional a que o texto se destinava estaria predisposta a entender de forma adequada ao objetivo. Isto é: não restam dúvidas de que Fernão Lopes escreveu para um rei à cabeça de uma corte que precisava de uma narrativa oficial que apoiasse a legitimidade de uma sucessão pouco convencional. As emoções foram, tão-só, um dos mecanismos que utilizou. 


\section{Referências bibliográficas:}

\section{Fontes impressas}

AFONSO, Pedro (Conde de Barcelos) - Crónica Geral de Espanha de 1344. Reconstituição do ms. L da Crónica Geral de Espanha de 1344 (2. ${ }^{a}$ Parte) de Sílvia Miranda. Lisboa, Faculdade de Letras da Universidade de Lisboa, 2013. Relatório de Estágio de Mestrado.

AFONSO, Pedro (Conde de Barcelos) - Crónica Geral de Espanha de 1344. Reconstituição do ms. L da Crónica Geral de Espanha de 1344 (1. ${ }^{a}$ Parte) de Marta Pedrosa. Lisboa: Faculdade de Letras da Universidade de Lisboa, 2013. Relatório de Estágio de Mestrado.

AFONSO, Pedro (Conde de Barcelos) - Crónica Geral de Espanha de 1344. Edición Crítica del Texto Español de la Crónica de 1344 que ordenó el Conde de Barcelos don Pedro Alfonso, ed. Parcial de Diego Catalán e María Soledad de Andrés. Madrid: Gredos, 1970.

AFONSO, Pedro (Conde de Barcelos) ou ALFONSO XI - Crónica Geral de Espanha de 1344. Crónica de 1344. Edición crítica y estudio. Vol. II, Ed. Crítica de Ingrid Vindel Perez, Bellaterra: Universitat Autònoma de Barcelona, 2016. Tese de Doutoramento. Disponível em https://ddd.uab.cat/record/167824?ln=ca

Crónica de Portugal de 1419. Edição crítica com introdução e notas de Adelino de Almeida Calado. Aveiro: Universidade de Aveiro, 1998.

DUARTE, (rei) - Leal Conselheiro [Em linha]. Edição Eletrónica, Ed. João Dionísio. Wisconsin: University of Wisconsin Digital Collections, UW-Madison Libraries, 2012. [Consultado a 19 abril 2018]. Disponível em http://uwdc.library.wisc.edu/lealconselheiro-electronic-edition

DUARTE, (rei) - Livro dos Conselhos de El-Rei D. Duarte. Ed. João José Alves Dias. Lisboa: Editorial Estampa, 1982. 
LOPES, Fernão - Crónica de D. Fernando. Edição Crítica, introdução e índices de Giuliano Macchi. 2. ${ }^{a}$ Ed. Revista. Lisboa: Imprensa Nacional-Casa da Moeda, 2004.

LOPES, Fernão - Crónica de D. Pedro. Edição Crítica, introdução e índices de Giuliano Macchi. 2. ${ }^{a}$ Ed. Revista. Lisboa: Imprensa Nacional-Casa da Moeda, 2007.

LOPES, Fernão - Crónica de Dom João I. Primeira Parte. Edição Crítica e Notas de Teresa Amado, com a colaboração de Ariadne Nunes, Carlota Pimenta e Mário Costa. Lisboa: Imprensa Nacional-Casa da Moeda, 2018.

LOPES, Fernão - Crónica del Rei Dom Joham I de Boa Memoria e dos Reis de Portugal o Decimo, Parte II. Edição crítica de William J. Entwistle. Lisboa: Imprensa NacionalCasa da Moeda, 1977.

\section{Estudos}

ALTHOFF, Gerd - "Ira regis: Prolegomena to a history of royal anger". in ROSENWEIN, Barbara H. (ed.) - Anger's past: the social uses of an emotion in the Middle Ages. Ithaca: Cornell University Press, 1998, p. 59.

BERGQVIST, K. - "Tears of Weakness, Tears of Love: Kings as Fathers and Sons in Medieval Spanish Prose”. in FÖRNEGÅRD, Per; KIHLMAN, Erika; ÅKESTAM, Mia; ENGWALL, Gunnel - Tears, Sighs and Laughter: Expressions of Emotions in the Middle Ages. Estocolmo: KVHAA, 2017, pp.77-97.

BERLIN, Henry - "The willing reader of Duarte's Leal Conselheiro". Journal of Medieval Iberian Studies Vol. 5, n. ${ }^{\circ}$ (2013), 204-219.

BROOMHALL, Susan - Authority, Gender and Emotions in the Late Medieval and Early Modern England. Nova Iorque: Palgrave Macmillan, 2015. 
BROOMHALL, Susan (ed.) - Early Modern Emotions: An Introduction. Londres: Routledge, 2017.

DOUBLEDAY, Simon - “Anger in the Crónica de Alfonso X”. Al-Masaq Vol. 27, n. ${ }^{\circ} 1$ (2015) pp. 61-76.

FORONDA, François - "El miedo al rey: fuentes e primeras reflexiones acerca de una emoción aristocrática en la Castilla del siglo XIV”. e-Spania [Em Linha] 4 (dezembro de 2007) [Consultado a 19 abril 2018]. Disponível em https://journals.openedition.org/e-spania/2273

LYNCH, Andrew - "Emotional Community". in BROOMHALL, Susan (ed.) - Early Modern Emotions: An Introduction. Londres: Routledge, 2017, p. 3.

MUÑOZ FERNANDEZ, Ángela - "Llanto, palavras y gestos. La muerte e el duelo en el mundo medieval hispânico (morfologia ritual, agencias rituales y controversias)". Cuadernos de historia de España 83 (2009), pp. 107-139.

NAGY, Piroska - Le don des larmes au Moyen Âge. Paris: Albin Michel, 2000.

NAGY, Piroska; BOQUET, Damien - Sensible Moyen Âge. Une histoire des émotions dans l'Occident Medieval. Paris: Seuil, 2015.

NOGALES RINCÓN, David - "Admiración, extrañeza y construcción del discurso narrativo de la crónica real. Emoción de la maravilla y representación política en la Castilla bajomedieval". e-Spania [Em Linha] 27 (junho de 2017), [Consultado a 19 abril 2018]. Disponível em http://journals.openedition.org/e-spania/26616

ORNING, Hans Jacob - "Royal anger between Christian doctrine and practical exigencies". Collegium medievale: interdisciplinary journal of medieval research 22 (2009), pp. 34-54. 
REDDY, William M. - The Navigation of Feeling. A Framework for the History of Emotions. New York, 2001.

RODRÍGUEZ PORTO, Rosa M. - "La Crónica Geral de Espanha de 1344 (ms. 1 A de la Academia de Las Ciências y la tradición alfonsí”. e-Spania [Em Linha] 25 (outubro de 2016), [Consultado a 19 abril 2018]. Disponível em http://journals.openedition.org/espania/25911

ROSENWEIN, Barbara H.; CRISTIANI, Riccardo - What is the History of Emotions?. Cambridge: Polity Press, 2018.

ROSENWEIN, Barbara H. - Emotional Communities in the Early Middle Ages. Ithaca \& London: Cornell University Press, 2006.

ROSENWEIN, Barbara H. (ed.) - Anger's Past. The social uses of an emotion in the Middle Ages. Ithaca and London: Cornell University Press, 1998.

SCHEER, Monique - "Are emotions a kind of practice (and this is what makes them have history)? A bourdieuian approach to understanding emotion”. History and Theory 51 (maio de 2012), pp.193-220.

SOUSA, Bernardo Vasconcelos e - "Medieval Portuguese Royal Chronicles. Topics in a discourse of Identity and Power". e-Journal of Portuguese History [Em Linha] Vol. 5, n. 2 (2007), [Consultado a 19 abril 2018]. Disponível em http://www.scielo.mec.pt/scielo.php?script=sci_arttext\&pid=S1645$\underline{64322007000200001 \& \operatorname{lng}=\text { pt\&nrm=iso. }}$.

VINDEL PÉREZ, Ingrid - Crónica de 1344. Edición crítica y estudio. Bellaterra, Universitat Autònoma de Barcelona, 2016. Tese de Doutoramento. Disponível em https://ddd.uab.cat/record/167824?1n=ca 
WHITE, Stephen D. - “The politics of anger”. in ROSENWEIN, Barbara H. - Anger's Past. The social uses of an emotion in the Middle Ages. Ithaca and London: Cornell University Press, 1998, pp. 135-149.

\section{COMO CITAR ESTE ARTIGO}

\section{Referência electrónica:}

OLAIA, Inês - "O rei que esmorece e a rainha sanhuda: a crise dinástica de 1383-1385 através das emoções nas crónicas de Fernão Lopes”. Medievalista 27 (Janeiro - Junho 2020). [Em linha] [Consultado dd.mm.aaaa]. Disponível em http://www2.fcsh.unl.pt/iem/medievalista/MEDIEVALISTA27/olaia2701.html ISSN 1646-740X.

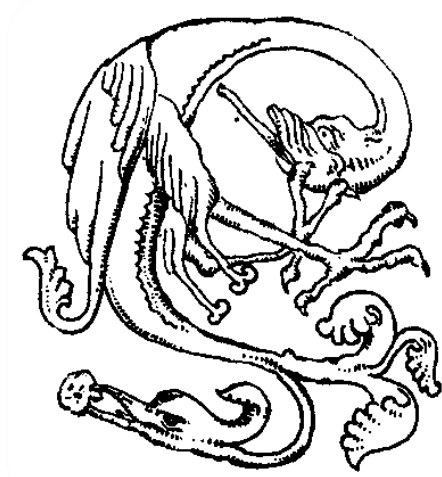

